\title{
Influence of milled glass fillers on the impact and compression after impact behavior of glass/epoxy composite laminates
}

\author{
K. Saravanakumar a , Harini Subramanian ${ }^{\mathrm{a}}$, V. Arumugam ${ }^{\mathrm{a}}$, H. N. Dhakal ${ }^{\mathrm{b} *}$ \\ ${ }^{a}$ Department of Aerospace Engineering, MIT campus, Chromepet, Anna University, Chennai-44, \\ Tamil Nadu, India \\ ${ }^{b}$ Advanced Materials and Manufacturing (AMM) Research Group, School of Mechanical and Design \\ Engineering, University of Portsmouth, Portsmouth, England, PO1 3DJ, United Kingdom
}

\section{Abstract}

The effects of milled glass fibre as fillers on the impact and post impact compression (CAI) behavior of glass/epoxy composite laminates is investigated. The milled glass fiber fillers $5 \%$ by weight of epoxy were incorporated into the glass/epoxy laminates by using ultra-sonication and mechanical stirring techniques then the results were compared with the baseline glass/epoxy laminate. The incident energy applied were 10, 15, 20, 25 and 30 Joules. The glass filler loaded samples exhibited higher peak force than the baseline samples. The compression strength of NonImpacted (NI) filler loaded samples was improved by $18 \%$ compared to the baseline samples. A good correlation between milled glass filler addition into the matrix of glass/epoxy composites and the improvement in impact damage and residual CAI behaviors were evident. The improved impact and CAI properties of milled glass filled composite indicate that this composite is a good candidate for load bearing applications.

Keywords: Glass fibre reinforced plastics (GFRP); Fracture toughness; Scanning electron microscopy (SEM); Compression after impact (CAI).

\footnotetext{
* Corresponding author: Tel: + 44 (0) 239284 2582; fax: + 44 (0) 2392842351.

E-mail: hom.dhakal@port.ac.uk (H. N. Dhakal)
} 


\section{Introduction}

High performance laminated composites have been extensively used in several industries such as aerospace, marine, automobile, wind turbines due to their excellent in-plane specific strength and stiffness. However, fiber reinforced plastic (FRP) composites are highly susceptible to internal damage during transverse loading making them susceptible to impact and post impact damage. In addition, this scenario leads to common failure modes such as matrix deformation, micro-cracking, interfacial debonding, fiber splitting, fiber breakage and fiber pull-out. Delamination is a predominant failure mode, which can cause reduction in strength and stiffness of composites leading to growth of damage and ultimate failure. The structural integrity of composite materials is influenced by even a small tool drop and debris impact on composite parts during their service life leading to loss of residual flexural and compression strengths [1-3]. An analysis of these failure modes requires an understanding of residual internal stresses created due to various failure modes. Hence, these residual strengths and damages are assessed and understood to ensure the structural integrity of the composite laminates. Mostly, the post impact compressive strength of impact damaged laminates are evaluated to design the composite laminates with damage tolerance approach. Naik et al. [4] investigated the impact and post impact compressive behaviours of glass/carbon hybrid composite laminates by altering the stacking sequence. Gustin et al. [5] investigated the low-velocity-impact of Kevlar/Carbon fiber composites. They observed that reduction in CAI strength was minimised by incorporating Kevlar layers to the laminates. Caminero et al. [6] presented results on the effects of thickness and ply-stacking sequence on the compression after impact (CAI) strength of carbon fibre reinforced epoxy laminates. Their results indicated that the thicker laminates have higher post impact compression strength, which was 
influenced by incident impact energies. Furthermore, it concluded that the CAI strength was further influenced by the ply-stacking sequence.

The impact resistance and damage tolerance of the glass fiber reinforced composite laminates are better than the carbon fiber reinforced laminates, due to their higher strain to failure resulting in higher energy absorption [7, 8]. Ibekwe et al. [9] studied the impact and compression after impact behaviours of laminated composites at low temperatures. The results from their work suggest that cross-ply laminates have higher impact resistance than the unidirectional laminates.

De Freitas and Reis [10] characterised the failure mechanism of composite laminates subjected to compression after impact. Their results exhibited that the delaminated area increased due to impact and post impact compressive strength as a function of absorbed energy. Moreover, the impact response of the composite laminates has been a major concern in engineering applications because of lack of full understanding of the effect of impact and post impact loadings on the failure mechanisms, low impact damage resistance and low transverse mechanical properties [11, 12]. Over the past few years, researchers in composites industry have been focusing on improving resin dominated properties by incorporating micro-sized soft organic/rigid inorganic fillers. It has also been observed that these fillers considerably improved the fracture toughness of the composites [13-15].

Recent advancement in nano-particles like Nano clay, Carbon nanotubes (CNT) and Nanofiber has shown potential to improve the mechanical properties of thermosets and their laminates [16]. Crack pinning, CNT bridging, crack arresting, crack deflection were the prominent toughening mechanisms reported in CNT modified epoxy matrix system [18-20]. Similarly, the work carried out by Nezhad and Thakur [21] on the effects of incorporating varied wt. \% of graphite carbon 
nanoparticles (CNPs) into epoxy matrix suggested a significant improvement in mechanical performance due to the effect of morphological changes. However, it was highlighted to be challenging to achieve uniform dispersion and proper interfacial bonding with these nanofillers [22, 23]. Kostopoulus et al. [17] tested the impact and post impact properties of CFRP composite laminates. They reported that addition of multi-walled carbon nanotubes (MWCNTs) had no effect on delamination area and absorbed energy. Despite the advantages, employing CNT's into epoxy matrix increases the viscosity and hence the processing cost is inflated [24].

Similarly, waste materials generated by the Fiber Reinforced Plastic (FRP) composite industries often end up in landfills, which causes negative environmental impacts. According to recent review undertaken by Mgbemena et al. [25], which highlighted that advanced composite materials can offer tailored materials properties while maintaining environmentally friendly structures. Hence, recycling of polymeric waste materials would contribute to a more sustainable and economic FRP industry [26]. These issues direct to utilisation of recycled milled glass fiber as an alternative filler for laminated composites.

In general, all the aforementioned research works evidently exhibit the possibility of enhancing the damage tolerance of composite laminates by incorporating the recycled milled glass fibers as an alternative for commercial fillers. In this work, the influence of milled glass fiber fillers on the low velocity impact behavior of glass/epoxy composites laminates have been investigated. The milled glass fiber fillers were added to the epoxy matrix of the laminate, $5 \%$ by weight fraction using ultra sonication. The filler loaded samples were subjected to drop weight impact test at different energy levels (10J, 15J, 20J, 25J and 30J). The parameters such as impact force, absorbed energy, residual deformation and damage area were investigated and the results are correlated with the baseline samples. 


\section{Experimental procedures}

\subsection{Materials and fabrication of composite laminates}

The composite laminates with cross-ply stacking sequence of [0/90]4s configuration was fabricated from unidirectional 220 GSM Glass fabric and LY556 Epoxy resin with HY951 hardener. Initially, milled glass fiber fillers were mixed in the epoxy resin (5 wt.\% of epoxy) to distribute the filler uniformly by mechanical stirring and Ultra-sonication. Subsequently, the mixture was degassed to remove entrapped air bubbles. Afterward, hardener was added to the mixture at a ratio of 1:10 by weight and further stirred to initiate the curing process. The glass fiber and epoxy resin were taken in the ratio of $1: 1$ by weight. The laminates were fabricated by hand layup method in combination with compression moulding technique at room temperature using a $50 \mathrm{kN}$ machine at a pressure of $5 \mathrm{MPa}$. Similarly, baseline glass/epoxy laminates without milled glass fiber fillers were fabricated as above. ASTM D7137M-12 standard compression after impact specimens of size $150 \mathrm{~mm} \mathrm{X}$ $100 \mathrm{~mm}$ were cut from the fabricated laminate of dimension 500mm X 500mm using abrasive water-jet cutting machine. The nominal thickness of the laminate was $\pm 4.5 \mathrm{~mm}$. All the laminates were cured under room temperature for 24 Hrs.

\subsection{Drop weight impact test}

Drop weight impact test was performed utilising a Fractovis drop weight impact tester at room temperature. Low velocity impact response of the glass/epoxy composite laminates was investigated at different impact energy levels (10J, 15J, 20J, 25J and 30J). The samples were impacted with hemispherical steel impactor of $12.7 \mathrm{~mm}$ diameter with a mass of $1.926 \mathrm{~kg}$. The clamping system has a clamping force of $1000 \mathrm{~N}$ and the test was performed according to ASTM D7136M-05 standard. The impactor was dropped at the center of the specimen from selective 
heights to achieve the required impact energy level. A catcher mechanism was actuated to avoid multiple impacts on the samples. Impact parameters such as impact force, impact energy, maximum deformation and residual deformation were recorded during the impact test.

\subsection{Compression after impact (CAI) tests}

The Compression After Impact (CAI) tests was performed at room temperature, using an ASTM D 7137 fixture in a $100 \mathrm{kN}$ Tinius Olsen Universal Testing Machine (UTM) as per ASTM D7137M-12 standard to evaluate the residual compressive strength. The CAI specimens were clamped exactly on the fixture by adjusting four supporting plate for arresting the global buckling [28]. The compressive load is applied under constant displacement rate of $0.5 \mathrm{~mm} / \mathrm{min}$. The data acquisition system in the universal testing machine recorded the force-displacement history. The CAI strength $\left(\sigma_{C}\right)$ of the specimen is calculated using the equation (1).

$$
\sigma_{C}=\frac{F_{\text {Max }}}{(b \times d)}
$$

Where, $F_{M a x}, b$ and d denote the maximum failure load, the width and the thickness of the CAI samples, respectively.

\section{Results and discussion}

The low velocity impact behaviour was experimentally investigated for baseline glass/epoxy samples and filler loaded glass/epoxy samples.

Figure 1 shows typical load and energy versus time curves of baseline glass/epoxy samples and filler loaded glass/epoxy samples tested at different impact energy levels. The profile of these curves indicates that the load reaches a maximum value, followed by a drop after the peak load. 
The peak force, contact duration and absorbed energy have been found to increase with increase in impact energy. In all the cases of impact energy levels, the impactor rebounds after deforming the samples which represents no penetration has occurred [27]. In general, at low energy impact, the load-time response was observed to be smooth and symmetric during loading and unloading, indicating occurrence of progressive damage. However at 25J and 30J impact energy levels, sudden drop after the peak load was observed which is attributed to unstable progression of delamination damage. The severity of damage relies on the level of load drop observed. It can be observed that the filler loaded samples exhibit only fewer oscillation at peak load promoting less damage than the case of baseline samples. Subsequently for all the impact energy levels, the filler loaded samples exhibited higher peak load, lesser contact duration and absorbed energy than the baseline samples. The peak load and the contact duration experienced by the impactor during an impact event indicates the load bearing capacity of the composite laminates, which is associated with the initial rigidity of the samples [28]. This observation confirms that higher impact load bearing capacity can be achieved by incorporation of milled glass fiber fillers.

Three samples were tested in each category and the average values were taken to evaluate the peak load, absorbed energy, time taken to peak load, maximum deformation, residual deformation and CAI strength for each set of samples. The results for different impact energy levels are summarised in Table 1.

Figure 1 further depicts the damage initiation, growth and change in specimen stiffness. It can be noted from figures 1(a) and 1(b) that the sudden load drop was observed at impact energy levels of $20 \mathrm{~J}, 25 \mathrm{~J}$ and $30 \mathrm{~J}$, which represents the incipient damage due to delamination $[29,30]$. This damage occurred in both baseline glass/epoxy and filler loaded glass/epoxy samples. From the curves of energy versus time in Figure 1, the impact energy can be characterised into different 
stages. In Stage I, the absorbed energy is relatively low attributing to small dent/deformation of the samples along the thickness. In Stage II, change in slope of the curve is observed due to increase in contact area of the impactor with the sample. Finally, in Stage III the plateau of the curve begins and loss of contact between Impactor and sample occurs [31].

Initially in an impact event, the impact energy is absorbed by the composite materials through elastic deformation till threshold energy is reached. However, beyond a certain threshold energy, the impact energy is absorbed through elastic deformation and creation of damage through different failure modes. In general, the impact energy is the amount of energy given to the sample by impactor. The total amount of energy dissipated by the sample through formation of damage is denoted as absorbed energy and the remaining energy, which is the difference between impact energy and absorbed energy, is retained by impactor in rebound. It can be observed that, at all the impact energy levels, the absorbed energy of baseline glass/epoxy samples is higher than the filler loaded glass/epoxy samples representing the occurrence of substantial damage.

Figure 2 (a) shows the energy profile diagram plotted between absorbed energy and impact energy for both baseline GFRP Samples and Filler loaded samples. It can be observed from the figure that the equal energy line represents that absorbed energy is equal to impact energy. Here, in all the cases of impact energy levels (10J, 15J, 20J, 25J, and 30J) no perforation has occurred. It can be seen that at 10J impact energy level, the low velocity impact behaviour of filler loaded samples is better than the baseline glass/epoxy samples. At this impact energy level, the absorbed energy of baseline glass/epoxy samples is $42 \%$ higher than the absorbed energy of the filler loaded samples. Similarly, at $15 \mathrm{~J}$ and $20 \mathrm{~J}$ impact energy levels, the baseline glass/epoxy samples absorbed more energy than the filler loaded sample. In contrast, at these energy levels the energy absorbed by the baseline samples is only $5 \%$ and $10 \%$ more than the filler loaded samples. As the impact energy 
was further increased to $25 \mathrm{~J}$ and $30 \mathrm{~J}$, the filler loaded samples exhibited slightly higher energy absorption compared to the baseline glass/epoxy samples [17]. This increase in energy absorption is attributed to additional energy dissipation mechanisms such as crack deflection, interlocking of filler/matrix interface and filler debonding/pullout. However, the delamination damage was found to be reduced in the filler loaded samples compared to the baseline samples, in spite of higher energy absorptions at $25 \mathrm{~J}$ and $30 \mathrm{~J}$ impact energy levels. From Figures 5 and 6 , it is evident that the incorporation of milled glass fiber filler in glass/epoxy laminates has reduced impact damage area and promoted better impact performance in comparison with the baseline glass/epoxy laminates.

Figure 3 represents the damage degree and residual deformation plot for both baseline samples and filler loaded Samples. The progression and accumulation of damage during an impact event can be investigated from the damage degree. Damage degree is defined as the ratio of absorbed energy to the given impact energy. The damage degree is unity when absorbed energy equals the impact energy, indicating the penetration of the sample. In general, the damage degree is a measure of the extent of deterioration in the structural integrity of laminates during an impact event. It is also known that the residual deformation or permanent deformation is the indentation experienced after an impact event on the surface of the composite laminate. It is worthy to note that, no penetration has occurred for all the cases of impact energy levels considered. It is observed from figure 3 (a) that, damage degree increases with increase in impact energy levels which indicates the progression of damage. It is also evident that the addition of milled glass fiber filler on glass/epoxy laminates decreased the damage degree showing enhanced impact resistance of the composite laminate. It was found that inclusion of fillers enhanced the adhesion between the fiber/matrix interface promoting efficient load transfer and reduced damage size. 
From Figure 3 (a) and (b), as the impact energy increases, the damage degree and residual deformation have been observed to increase owing to accumulation of damage. However, at higher impact energy levels of $25 \mathrm{~J}$ and $30 \mathrm{~J}$, the damage degree for both the baseline and filler loaded samples are similar, due to higher energy absorption capability and subsequently higher damage progression. Yet, the permanent deformation of the filler loaded sample was observed to be lesser than the baseline samples which evidences that incorporation of milled glass fiber fillers has improved the impact damage resistance in glass/epoxy composite laminates.

Figure 4 (a) shows variation of the velocity of impactor and deformation for various impact energy levels. It is well known that, during the initial stage of impact, the velocity of the striker is higher. As the velocity becomes zero, maximum deformation of the samples occurs. This instant of time is known as the bounce point. The curve follows a parabolic trend, indicating that no perforation has occurred in all the impact energy cases. From Figure 4 (a), it can be observed that the bounce point occurs earlier for the filler loaded samples than the baseline samples. In general, the ratio of the rebound velocity to impact velocity $\left(\mathrm{V}_{\mathrm{R}} / \mathrm{V}_{\mathrm{I}}\right)$ decreases with increasing impact energy which illustrates the increasing damage in the samples. If the ratio is equal to 1 , then the impact event is purely elastic [32]. The velocity ratio was found to be higher for filler loaded samples exhibiting higher elastic energy than the baseline samples. Elastic energy is the amount of energy which will not be transferred to the samples for creating permanent damage. In contrast this energy will be utilised by the impactor for rebounding. As the impact energy level increases, more energy is expended for forming damage on the samples than for rebound of the impactor. It is also observed that amount of elastic energy decreases with the increasing impact energy which evidences that more energy is absorbed by the samples at higher impact energy levels and thus resulting in more damage area which can be seen from Figures 5 and 6. The rate of change in velocity (deceleration) 
was also higher for the filler loaded samples, which indicates that incorporation of the milled glass fiber fillers enhances the impact resistance of the composite laminates. Overall, the maximum deformation and the bounce time of the filler loaded samples were lower compared to the baseline samples.

\subsection{Damage process and damage area during $L V I$}

Composite laminates exhibit poor impact resistance due to the premature failure during a Low Velocity Impact (LVI) event by transverse matrix cracking, fiber matrix interface debonding. This can be enhanced by improving the inter-laminar properties of brittle epoxy matrix by incorporation of fillers.

The front and back surface of the impact damaged laminates were examined for assessing the extent of the damage. The damage area measurement was carried out in order to evaluate the delamination area induced during impact damage. The quantification of delamination area was performed using post processing image $\mathrm{J}$ software. Figure 5 shows the projected delamination area of damaged samples at different impact energy levels. Figure 6 verifies that filler loaded samples exhibit reduced damage area than the baselines samples. Incorporation of milled glass fiber filler enhanced the delamination resistance during impact loading.

In general, at low impact energy level (10J) only localised matrix cracking was found to occur at the impact site due to higher inter-laminar shear stress generated during impact loading. In the baseline samples local indentation occurred at the impact site associated with minor matrix cracking. In other words, matrix cracking occurred under the edge of the impactor due to the high transverse shear stress. However, no dent/indentation was observed on the impacted surface of the filler loaded samples exhibiting higher impact resistance due to improved matrix properties, which 
can be seen from Figure 7. The stiffness of the material will not degrade significantly due to localised matrix cracking. However, this internal damage increases significantly with increase in impact energy, which is related to the ply delamination, which is associated with degrading interlaminar bonds.

As the impact energy level increases, the samples absorb more energy and the damage area on the samples also increases due to the tensile, shear matrix cracking and fiber fracture. At the intermediate energy level, both matrix cracking and delamination occur at the local impact zone. It can be seen from Figures 5 and 6, that the filler loaded samples exhibit lower impact damage area than the baseline samples due to enhanced fracture toughness of the filler loaded samples.

At moderate impact energy levels (15J and 20J), higher contact force induces a transverse shear crack which leads to critical matrix cracking, further resulting in delamination.

At 20J impact energy level, it can be observed that fiber breakage is clearly visible on the baseline samples which occurred due to the higher local stresses and indentation effect on the impacted site (front surface), and higher bending stresses on the non-impacted site (rear surface). Conversely, it can be seen from Figure 7 that the intensity of the damage is relatively minor in the filler loaded specimens.

Moreover, at higher impact energy levels, the major contribution to energy absorption is from fiber breakage. It can be observed from Figure 1 that the filler loaded samples exhibited higher energy absorption than the baseline samples. The absorbed energy of the filler loaded samples was slightly higher than the baseline samples displaying that presence of filler in the glass/epoxy composite is significant at higher impact energy levels. It can be seen in Figure 7 where fiber breakage has occurred both on the top and bottom surface of the laminates indicating higher energy absorption. 
It can also be observed from figures 5 and 6 that the damage area on the rear surface of impacted sample is greater than the front surface. At $25 \mathrm{~J}$ and 30J impact energy levels, the entire failure modes, that is, matrix cracking, delamination and fiber breakage occurred progressively in baseline samples. Fiber failure occurred on the front and rear surface of the laminates revealing that the failure occurred due to localised stress concentration below the impacted site and higher bending stress on the non-impacted site. It is evident that higher energy levels yield more detrimental damage. It is clear from the results that there is definitive correlation between increased in energy applied and the damage extent and that the severity of the damage developed.

\subsection{Scanning electron microscopy (SEM)}

In order to investigate the microstructural damage, scanning electron microscopy was performed on both baseline and filler loaded samples. The samples were placed on the holder and coated with gold to prevent charge build-up through electron absorption. A $12 \mathrm{kV}$ accelerated voltage was applied to accomplish desired magnification.

Figure 8 (a) shows the fracture surface of baseline samples, which exhibit smooth and brittle fracture. The coalescences of the micro crack in the resin rich interfaces causes formation of hackles pattern which occurred due to shear deformation [33, 34]. The delamination damage shows the poor bonding between the fiber/matrix interfaces (propagation of crack between the interfaces due to low fracture toughness of the epoxy matrix). The debonded fiber and minor fracture ridges exhibiting smooth and brittle fracture surface can be noticed in the figure. The observed failure behavior can be related to composite processing and parameters used to enhance the overall composite performance [35]. 
Figure 8 (b) shows the fracture surfaces of the filler loaded samples with rough fracture surface. The incorporation of filler in the glass/epoxy samples resulted in improved inter-laminar fracture toughness which prevents the developing delamination cracks. The fillers in the resin rich domain arrest crack propagation by preventing the expansion of matrix micro-cracking and by blunting the crack propagation (delamination). At higher impact energy levels, the filler loaded samples exhibit reduced delamination area and yet absorb additional energy through toughening mechanisms such as interlocking of filler/matrix interface, crack deflection and filler debonding/pullout, exhibiting additional energy dissipation mechanisms due to improved fracture toughness. Moreover, the presence of the milled glass fiber fillers in the glass/epoxy composites enhances the matrix properties and prevents the development of delamination by arresting the cracks between adjacent plies.

\subsection{Post impact compression strength}

Composite laminates are susceptible to impact loadings and some extreme conditions during their service life. Low velocity impacts create damage involving indentation, matrix cracking, interlaminar failure (fiber-matrix delamination) on the composite laminates often with no signs of damage on the surface. Such impact damage can reduce the residual strength of the composite laminates drastically. The residual damage tolerance of such composite laminates can be evaluated by compression after impact (CAI) test.

During CAI test, homogeneous compression causes the cracks to propagate normal to the loading direction from the impact point. Propagation of delamination occurs at the impact point and finally buckling of plies leads to ultimate failure of the structure. The compressive fiber failure is a key failure mechanism in CAI test, which occurs due to local buckling of fiber causing the kink band 
formation. In general, the residual strength is influenced by the delamination area which is a function of impact energy.

Figure 9 (a) shows the Compression After impact (CAI) strength of both baseline and filler loaded samples impacted at different energy levels. It can be observed that the residual CAI strength of the glass/epoxy samples decrease with the increase in impact energy. However, at all the impact energy levels, the filler loaded samples exhibited higher residual strength than the baseline samples attributing to the improved matrix properties (fracture toughness). In baseline samples, the residual strength for $10 \mathrm{~J}, 15 \mathrm{~J}, 20 \mathrm{~J}, 25 \mathrm{~J}$, and $30 \mathrm{~J}$ impact energy levels was found to be $6 \%, 14 \%, 20 \%, 24 \%$ and $26 \%$ lower respectively than the non-impacted baseline samples. Correspondingly, in filler loaded samples, the percentage reduction in residual strength for $10 \mathrm{~J}, 15 \mathrm{~J}, 20 \mathrm{~J}, 25 \mathrm{~J}$, and $30 \mathrm{~J}$ impact energy levels was found to be $5 \%, 9 \%, 12 \%, 17 \%$ and $21 \%$ respectively in comparison with nonimpacted filler loaded samples. The results of the CAI test for different energy levels are summarised in Table 1.

It was observed that, the compressive strength of Non-Impacted (NI) filler loaded glass/epoxy samples is $123.11 \pm 1.5(\mathrm{MPa})$ which is found to be $18 \%$ higher when compared to the $104.22 \pm$ $1.61(\mathrm{MPa})$ compressive strength of baseline glass/epoxy samples. The percentage improvement in residual compression strength of filler loaded samples for different impact energies (10J, 15J, $20 \mathrm{~J}, 25 \mathrm{~J}$, and $30 \mathrm{~J}$ ) was found to be $19 \%, 25 \%, 30 \%, 28 \%$ and $26 \%$ respectively higher than the impacted baseline samples. It can be observed that the addition of milled glass fiber fillers in the matrix of glass/epoxy composites enhanced the residual CAI strength which is attributed to strengthened interface, resulting in delayed fiber micro-buckling that causes the ultimate failure.

\section{Conclusions}


Experimental investigation on the influence of milled glass fiber fillers during impact and post impact compression behaviour of glass/epoxy composite laminate has been undertaken and the conclusions are summarised as follows:

1. The filler loaded samples exhibited higher peak load, lesser contact duration and increased absorbed energy than the baseline samples. This exhibited higher load bearing capacity in the composite laminates which is associated to initial rigidity of the samples. Incorporation of milled glass fiber filler in glass/epoxy laminates promotes good adhesion between fibers/ matrix interface. In the baseline samples, early failure tends to initiate at the interface region due to high shear stresses generated within the matrix. However, adding milled glass fiber filler enhances the fracture toughness behavior of the matrix through crack diversion and arrest, resulting in more efficient load transfer.

2. The peak load, energy absorbed, residual deformation and damage area increase with the increase in impact energy, which attributes to the damage developed during impact loading. The filler loaded samples absorbed less energy than the baseline samples at lower impact energies. However, at higher impact energies (25J and 30J), the energy absorbed by the filler loaded samples slightly increases due to additional energy dissipation mechanisms such as crack deflection, interlocking of filler/matrix interface and filler debonding/pullout.

3. In general, the degree of damage was observed to increase with increased impact energy. However, for filler loaded samples, it decreases due to enhanced mechanical properties of glass/epoxy laminate due to the incorporation of fillers. It was also found that the bounce point occurs earlier and the velocity ratio is higher for filler loaded samples, exhibiting higher elastic energy than the baseline samples. 
Overall, the CAI results showed that the use of milled glass fibre filler loaded samples exhibited a positive influence on the residual strength of composite samples investigated.

\section{Funding:}

This research did not receive any specific grant from funding agencies in the public, commercial, or not-for-profit sectors.

\section{References}

[1] M. Aktas, C. Atas, B.M. Icten, R. Karakuzu, An experimental investigation of the impact response of composite laminates, Compos Struct 87 (2009) 307-13.

[2] C. Atas, B.M. Icten, M. Küçük, Thickness effect on repeated impact response of woven fabric composite plates, Composites: Part B 49 (2013) 80-85.

[3] H.N. Dhakal, Z.Y. Zhang, N. Bennett, P.N.B. Reis, Low-velocity impact response of nonwoven hemp fibre reinforced unsaturated polyester composites: influence of impactor geometry and impact velocity, Composite Structures 94 (2012) 2756-2763.

[4] N.K. Naik, R. Ramasimha, H. Arya, S.V., Prabhu, N. Shama Rao, Impact response and damage tolerance characteristics of glass-carbon/epoxy hybrid composite plates. Composite Part B 32 (2001) 565-74.

[5] J. Gustin, A. Joneson, M. Mahinfalah, J. Stone, Low velocity impact of combinationKevlar/carbon fiber sandwich composites, Compos Struct 69 (2005)396406. 
[6] M.A., Caminero, I. García-Moreno, G.P. Rodríguez, Experimental study of the influence of thickness and ply-stacking sequence on the compression after impact strength of carbon fibre reinforced epoxy laminates, Polymer Testing 66 (2018)360-370.

[7] C. Thanomsilp, P. Hogg, Penetration impact resistance of hybrid composites based on commingled yarn fabrics, Compos SciTechnol 63 (2003)467-82.

[8] G.A. Bibo, P.J. Hogg, Influence of reinforcement architecture on glass-fibre/epoxy composite systems, Compos SciTechnol 58(1988)803-13.

[9] Ibekwe SI, Mensah PF, Li G, Pang SS, Stubblefield MA. Impact and post impact response of laminated beams at low temperatures. Compos Struct 79(2007)12-7.

[10] De Freitas $M$ and Reis L. Failure: mechanisms on composite specimens subjected compression after impact. Compos Struct 42 (1998) 365-373.

[11] M. Aktas, R. Karakuzu, Y. Arman, Comparison after impact behavior of laminated composite plates subjected to low velocity impact in high temperature, Compos Struct 89 (2009):77-82.

[12] H.N. Dhakal, V. Arumugam, A. Aswinraj, C. Santulli, Z.Y. Zhang, A. Lopez-Arraiza, Influence of temperature and impact velocity on the impact response of jute/UP composites, Polymer Testing 35 (2014)10-19.

[13] C.K. Riew, A.J. Kinlock, Toughened plastics I: science and engineering. Washington DC: American Chemistry Society; 1993.

[14] A.C. Garg, Y.W. Mai, Failure mechanisms in toughened epoxy resins - A review. Compos Sci Technol 31(1988)179-223. 
[15] Thostenson ET, Li C, Chou TW. Nanocomposites in context. Compos SciTechnol 2005;65(3-4):491-516.

[16] Behnam Ashrafi, Jingwen Guan, Vahid Mirjalili, Yunfa Zhang, Li Chun, Pascal Hubert, Benoit Simard, Christopher T. Kingston, Orson Bourne, Andrew Johnston.

Enhancement of mechanical performance of epoxy/carbon fiber laminates composites using single-walled carbon nanotubes. Composites Science and Technology 71 (2011) $1569-1578$.

[17] V. Kostopoulos, A. Baltopoulos, P. Karapappas, A. Vavouliotis, A. Paipetis. Impact and after-impact properties of carbon fibre reinforced composites enhanced with multi-wall carbon nanotubes. Composites Science and Technology 70 (2010) 553-563.

[18] Ruiz-Perez L, Ryston GJ, Fairclough JPA, Ryan AJ, Toughening by nanostructure. Polymer 49 (2008):4475-88.

[19] F. Gojny, M. Wichmann, B. Fiedler, K. Schulte, Influence of different carbon nanotubes on the mechanical properties of epoxy matrix composites - a comparative study, Compos. Sci. Technol. 65 (2005) 2300-2313.

[20] Johnsen, B.B, Kinloch AJ, Mohammed RD, Taylor AC, Springer S. Toughening mechanisms of nanoparticle-modified epoxy polymers. Polymer 48 (2007):530-41.

[21] Nezhad H.Y., Thakur VJ. Effect of morphological changes due to increasing carbon nanoparticles content on the quasi-static mechanical response of epoxy resin, Polymers, 10 (2018)) Article No. 1106. 
[22] Eslam M. Soliman a, Michael P. Sheyka b, Mahmoud Reda Tahaa. Low-velocity impact of thin woven carbon fabric composites incorporating multi-walled carbon nanotubes. International Journal of Impact Engineering 47 (2012) 39-47.

[23] Y. Zhu, C.E. Bakis, J. H. Adair, Effects of carbon nanofiller functionalization and distribution on interlaminar fracture toughness of multi-scale reinforced polymer composites, CARBON 50 (2012)1316-1331.

[24] E. Bekyarova, E.T. Thostenson, A. Yu, M.E. Itkis, D. Fakhrutdinov, T.W. Chou, R.C. Haddon, Functionalized single-walled carbon nanotubes for carbon fiberepoxy composites, J. Phys. Chem. C 11148 (2007) 17865-17871.

[25] Mgbemena, C.O., Li D, Lin M.F., Liddel P.D., Katnam K.B, Kumar V.T. \& Nezhad H. Y.. Accelerated microwave curing of fibre-reinforced thermoset polymer composites for structural applications: A review of scientific challenges, Composites Part A: Applied Science and Manufacturing, 115 (2018) 88-103.

[26] K. Hamad, M. K. F. Deri, Recycling of waste from polymer materials: An overview of the recent works. Polymer Degradation and Stability 98 (2013) 2801-2812

[27] P.N.B. Reis, J.A.M. Ferreira, Z.Y. Zhang, T. Benameur, M.O.W. Richardson. Impact strength of composites with nano-enhanced resin after fire exposure. Composites: Part B 56 (2014) 290-295.

[28] J. Jefferson Andrew, V. Arumugam, K. Saravanakumar, H.N. Dhakal, C. Santulli. Compression after impact strength of repaired GFRP composite laminates under repeated impact loading. Composite Structures 133 (2015) 911-920. 
[29] G.A. Schoeppner, S. Abrate, Delamination threshold loads for low velocity impact on composite laminates, Compos: Part A: Appl Sci Manuf 31(2000):903-15.

[30] A. Mishra, N.K. Naik, Failure initiation in composite structures under low velocity impact: analytical studies, Compos Struct 92(2010):436-44.

[31] C. Evci, M. Gulgec, An experimental investigation on the impact response of composite materials. Int J Impact Eng 43 (2012)40-51.

[32] C. Atas, O. Sayman, An overall view on impact response of woven fabric composite plates. Composite Structures 82 (2008) 336-345.

[33] F.H. Gojny M.H.G. Wichmann, B. Fiedler, K. Schulte, Influence of different carbon nanotubes on the mechanical properties of epoxy matrix composites- A comparative study, Compos SciTechnol 65 (2005) 2300-13.

[34] H. Qian, E.S. Greenhalgh, M.S.P. Shaffer, A. Bismarck, Carbon nanotube-based hierarchical composites: a review, J. Mater. Chem. 20 (2010) 4751.

[35] Lotfian S, Giraudmaillet C, Yoosefinejad A, Thakur V.J. \& Nezhad, H.Y. Electrospun piezoelectric polymer nanofiber layers for enabling in situ measurement in highperformance composite laminates, ACS Omega, 3 (2018) 8891-8902. 


\section{Figure captions:}

Figure 1: Load and energy versus time curves obtained from impact test (a) Baseline samples (b) Filler loaded samples.

Figure 2: (a) Energy profile diagram and (b) absorbed energy plot for both baseline samples and filler loaded samples, respectively.

Figure 3: (a) Damage degree and (b) Residual deformation plot for both baseline samples and filler loaded samples.

Figure 4: (a) Velocity-deformation plot and (b) Velocity ratio $\left(\mathrm{V}_{\mathrm{R}} / \mathrm{V}_{\mathrm{I}}\right)$ plot for both baseline samples and filler loaded samples.

Figure 5: Photographs of projected impact damaged area at different energy levels.

Figure 6: Variations in impact damage area for different impact energies.

Figure 7: Cross-sectional view of the damaged samples at different impact energy levels

Figure 8 (a) and (b) shows SEM micrographs of the fractured surface of baseline lass/epoxy sample and filler loaded sample, respectively.

Figure 9: (a) Compression after impact (CAI) strength and (b) \% improvement in residual strength for samples impacted at different energy levels. 


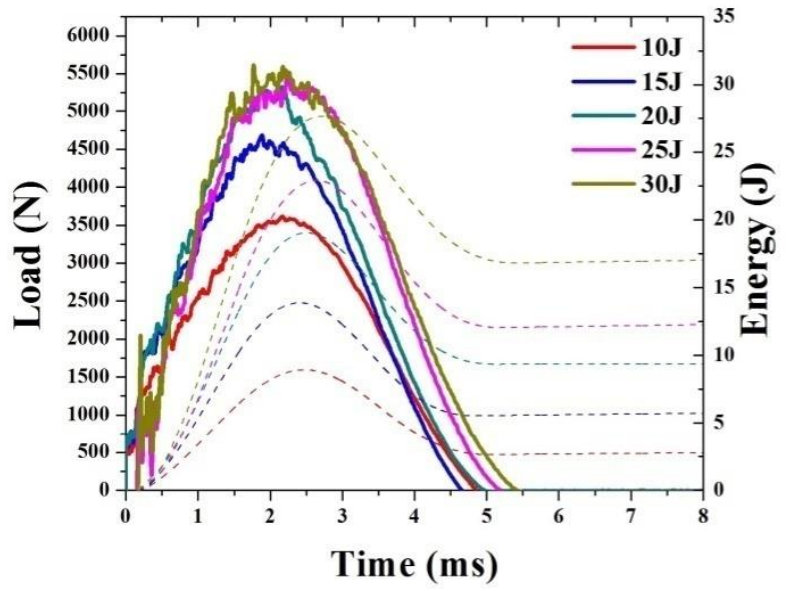

(a)

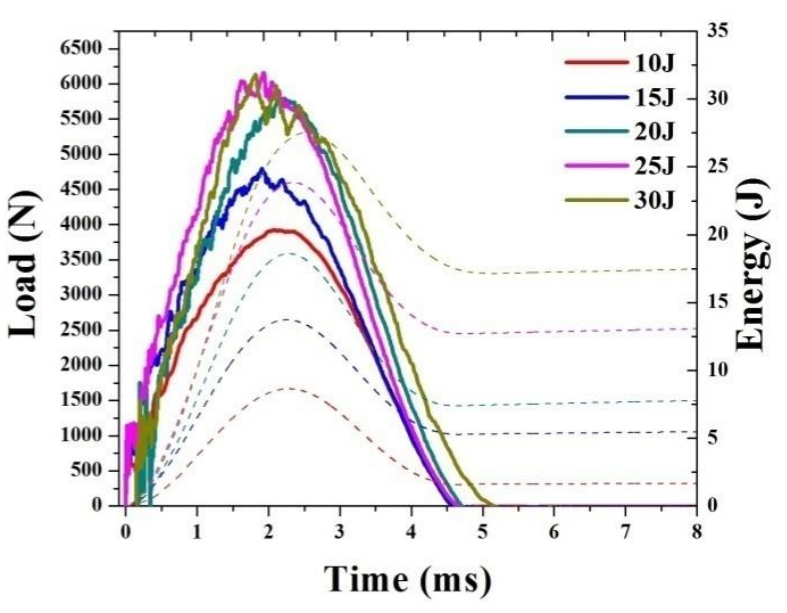

(b)

Figure 1: Load and energy versus time curves obtained from impact test (a)

Baseline samples (b) Filler loaded samples.
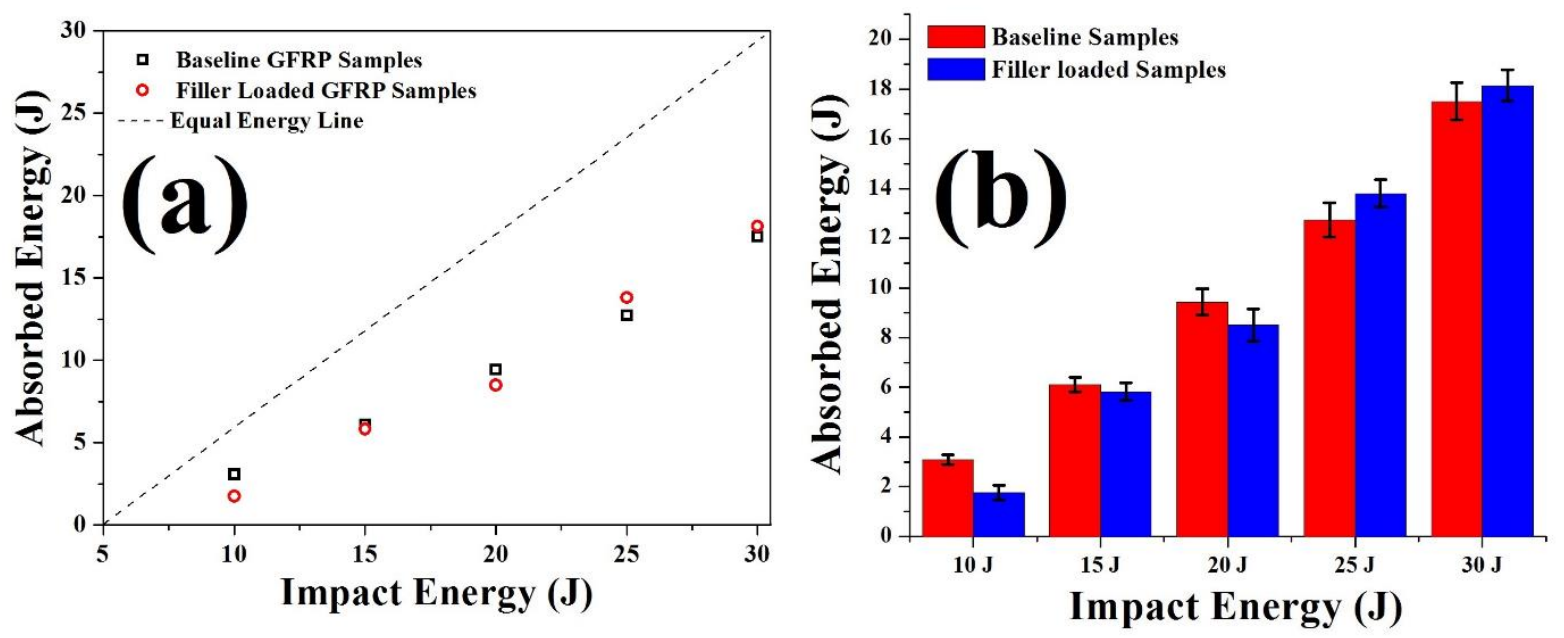

Figure 2: (a) Energy profile diagram and (b) absorbed energy plot for both baseline samples and filler loaded samples, respectively. 

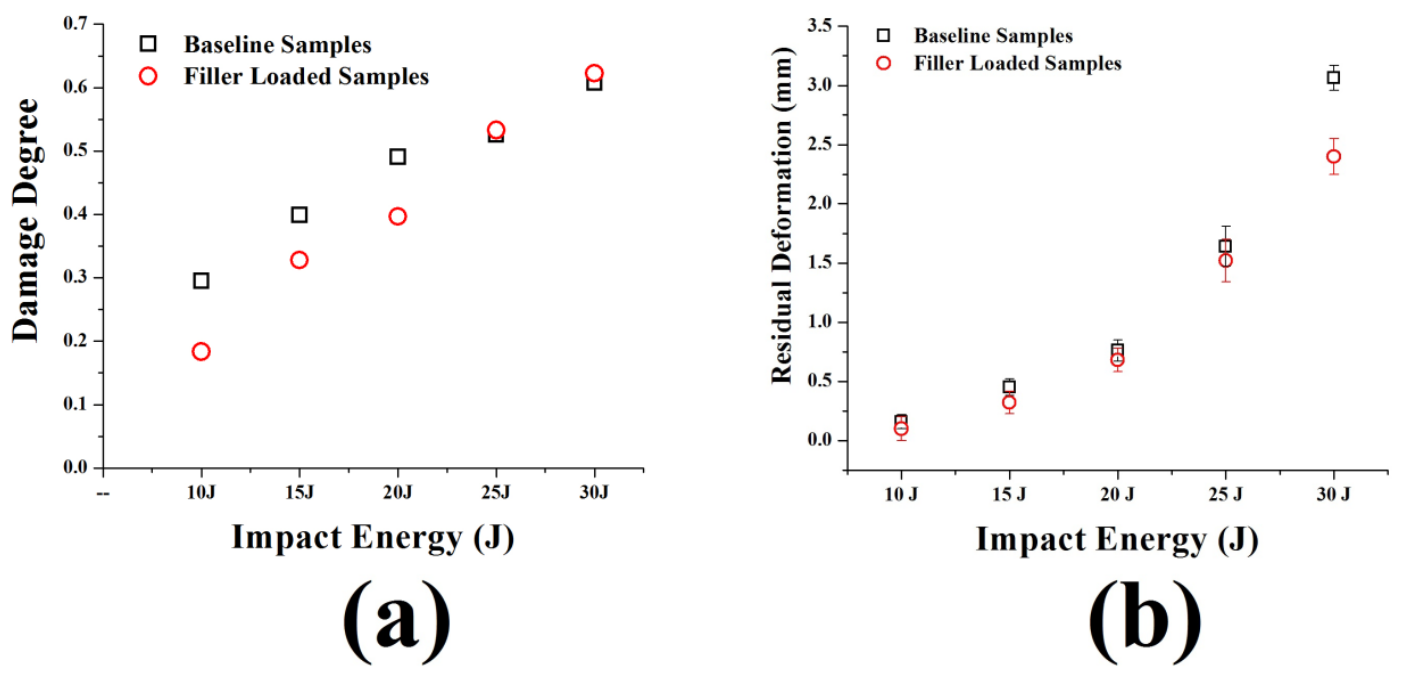

Figure 3: (a) Damage degree and (b) Residual deformation plot for both baseline samples and filler loaded samples.
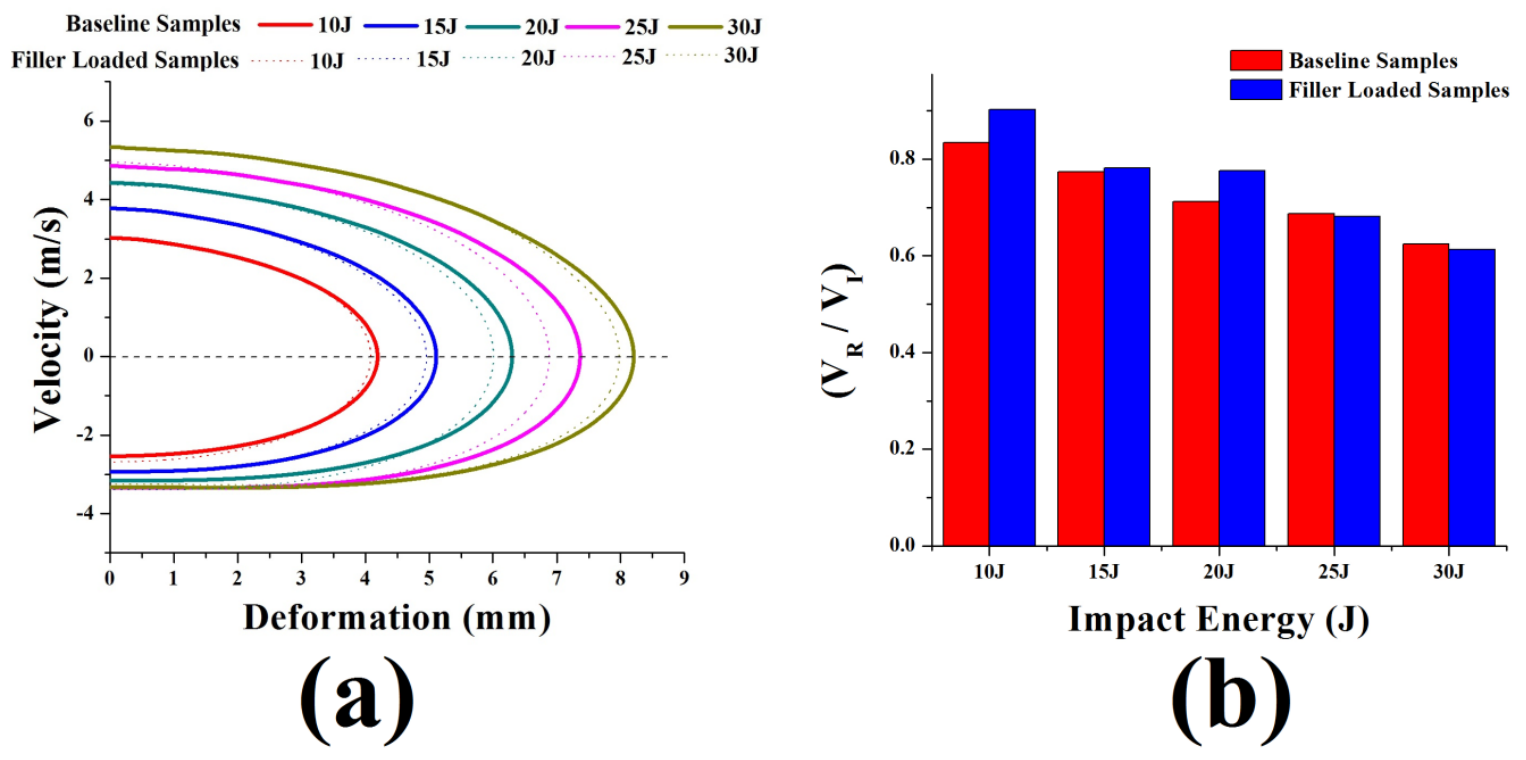
Figure 4: (a) Velocity-deformation plot and (b) Velocity ratio $\left(\mathrm{V}_{\mathrm{R}} / \mathrm{V}_{\mathrm{I}}\right)$ plot for both baseline samples and filler loaded samples.

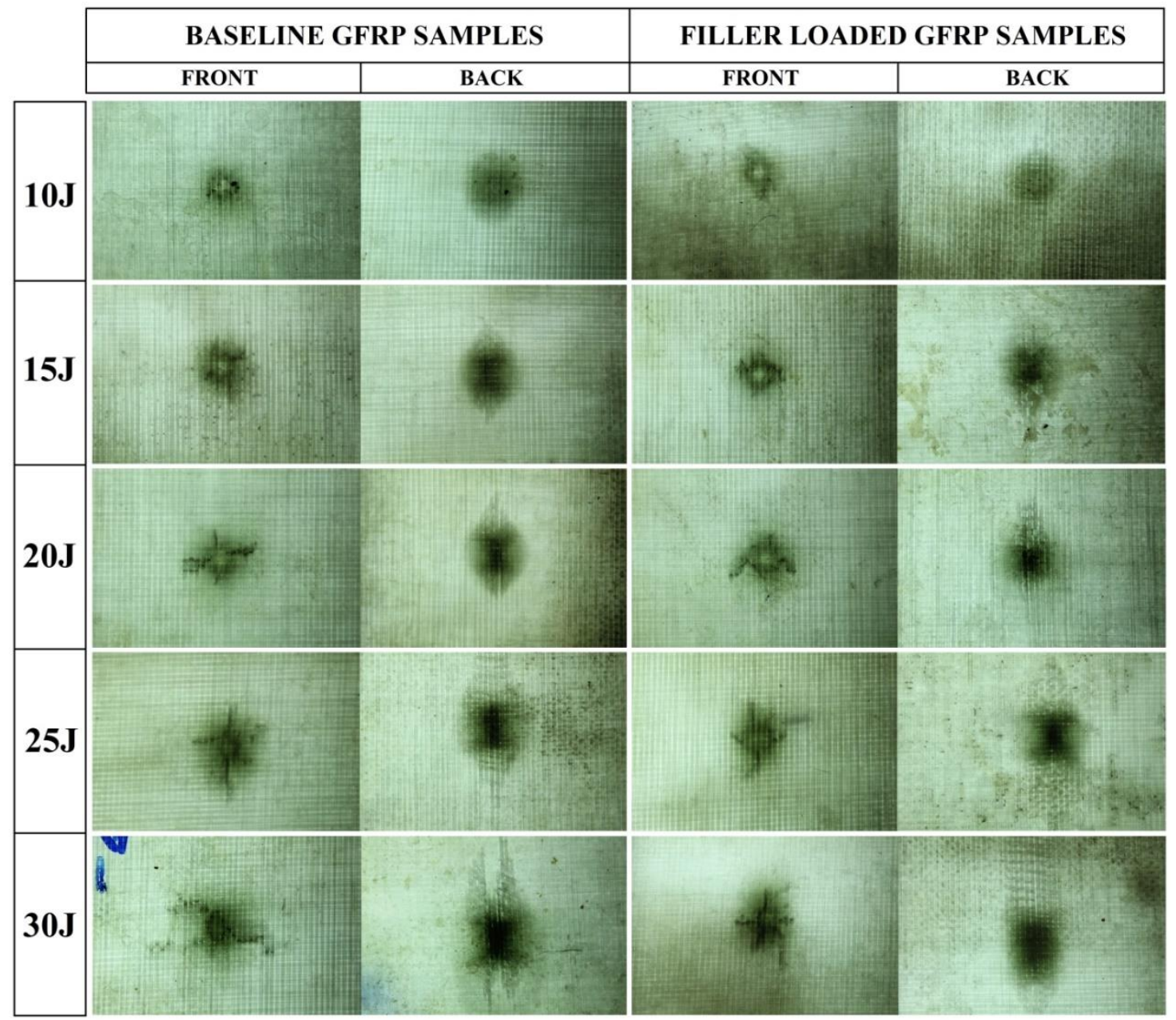

Figure 5: Photographs of projected impact damaged area at different energy levels. 


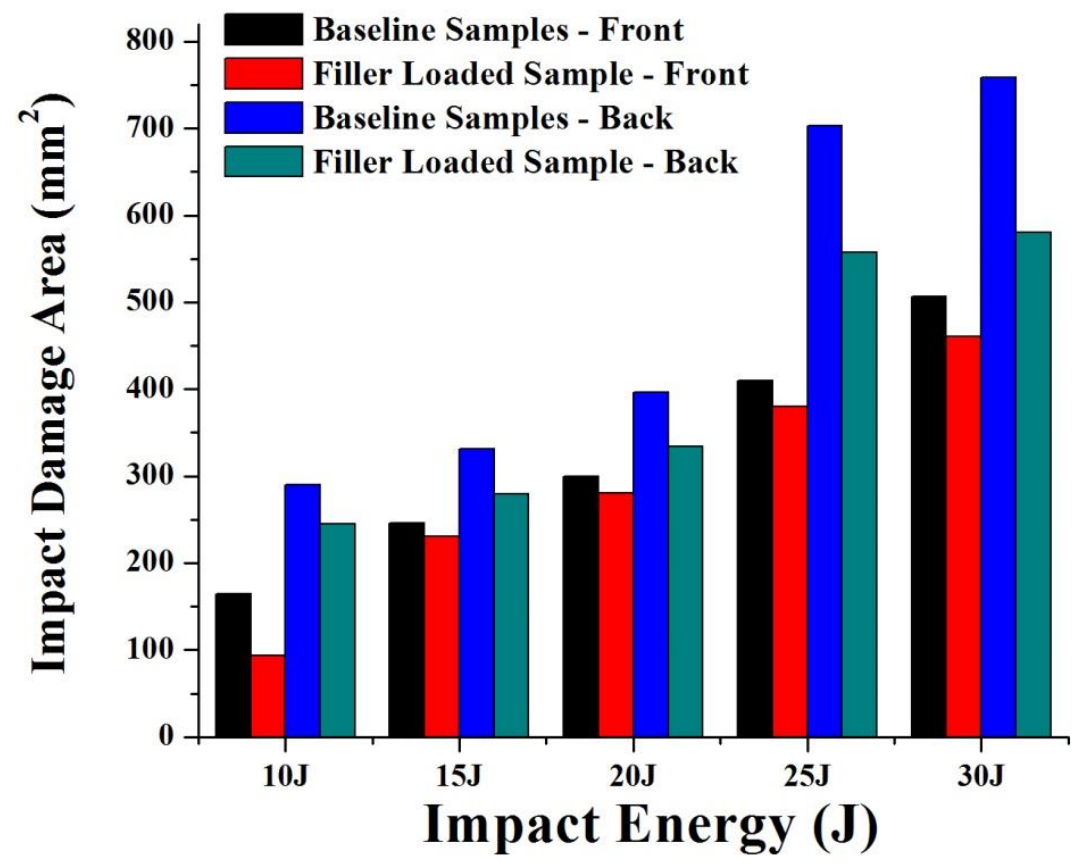

Figure 6: Variations in impact damage area for different impact energies. 


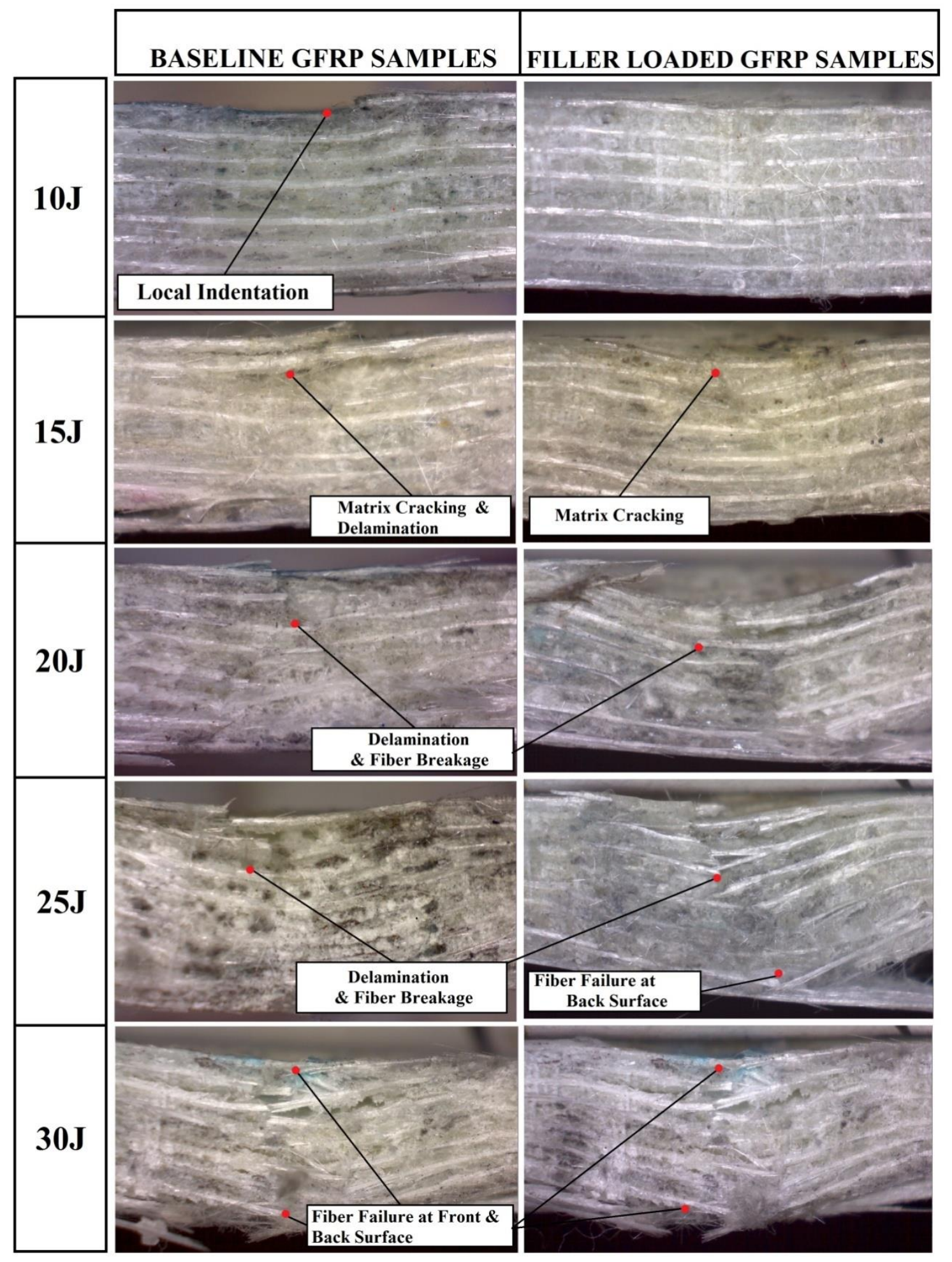

Figure 7: Cross-sectional view of the damaged samples at different impact energy levels. 


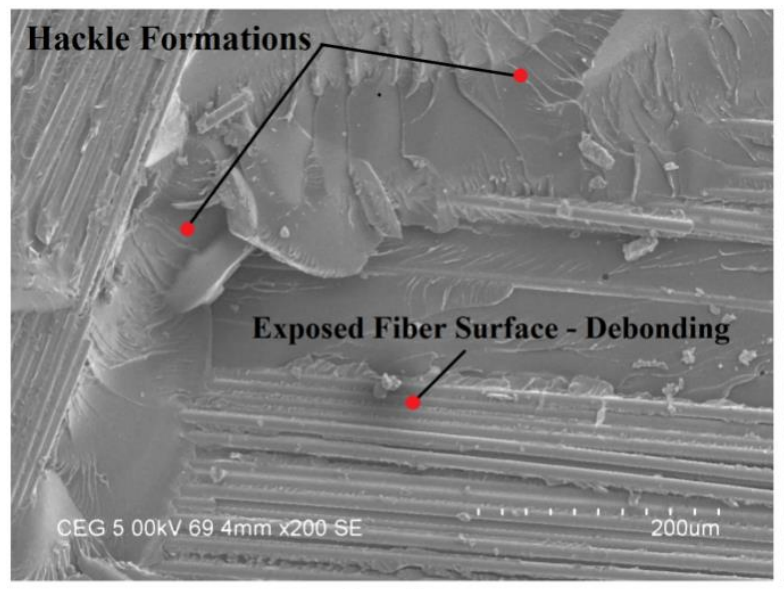

(a)

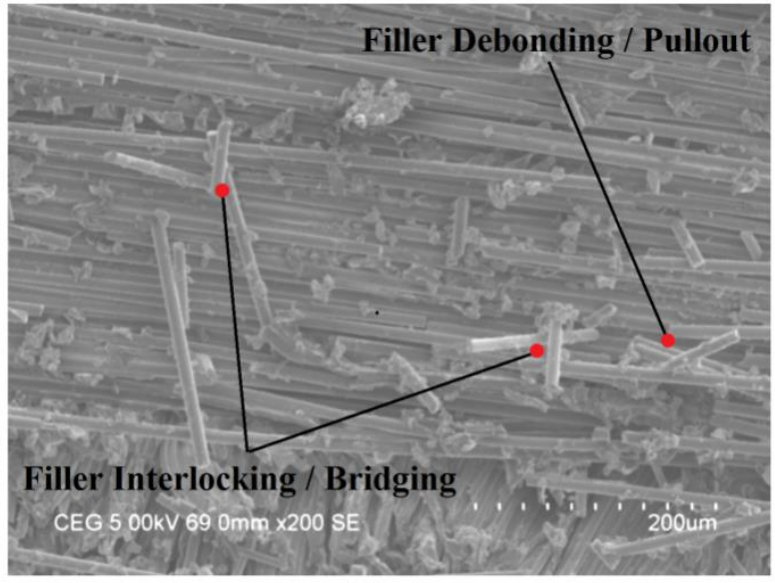

(b)

Figure 8 (a) and (b) shows SEM micrographs of the fractured surface of baseline glass/epoxy sample and filler loaded sample, respectively.
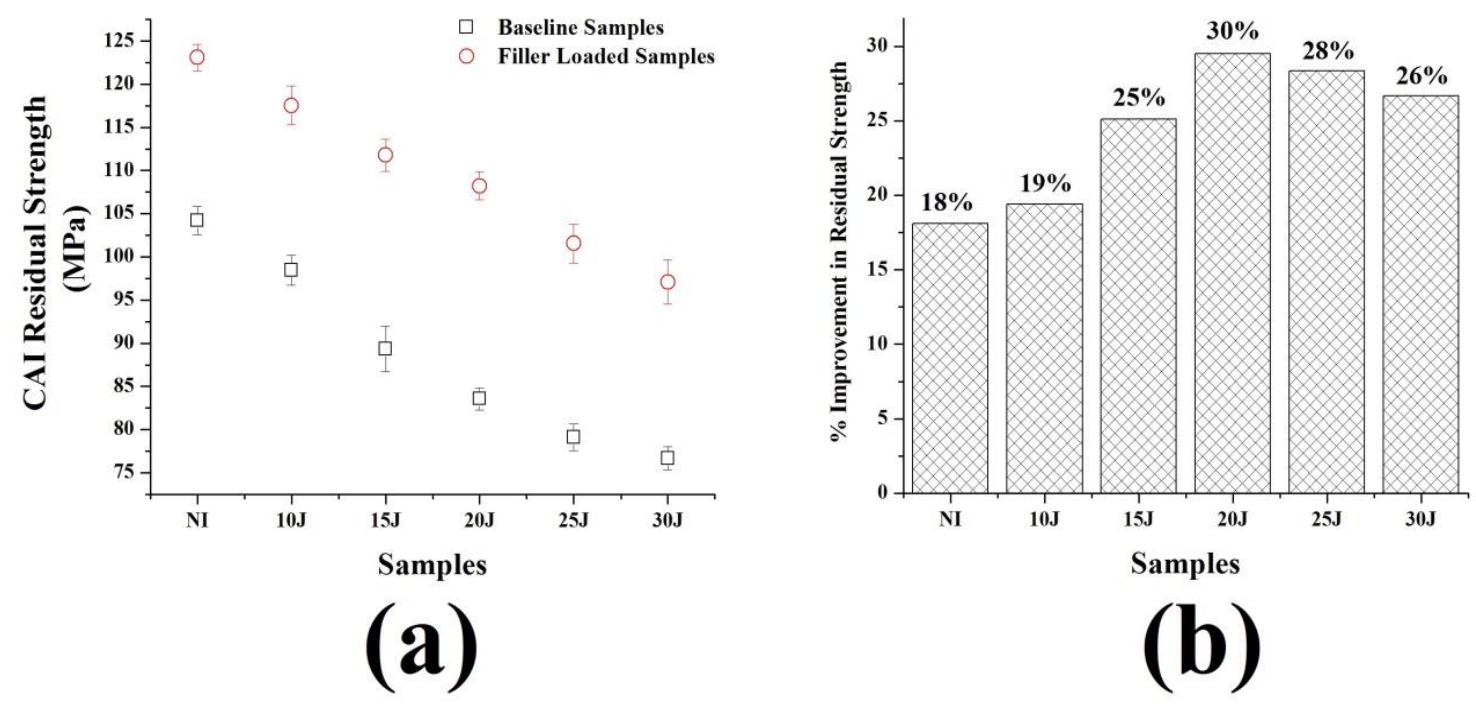

(b)

Figure 9: (a) Compression after impact (CAI) strength and (b) \% improvement in residual strength for samples impacted at different energy levels. 
Table captions:

Table 1: Impact test parameters, CAI strength of the baseline and filler loaded samples

(Figures in parentheses indicate standard deviation).

\begin{tabular}{|c|c|c|c|c|c|c|}
\hline \multicolumn{7}{|c|}{ Baseline Samples } \\
\hline $\begin{array}{c}\text { Impact } \\
\text { Energy } \\
\text { (J) }\end{array}$ & $\begin{array}{c}\text { Peak Load } \\
\text { (N) }\end{array}$ & $\begin{array}{c}\text { Max. } \\
\text { Deformation } \\
(\mathbf{m m})\end{array}$ & $\begin{array}{c}\text { Absorbed } \\
\text { Energy } \\
\text { (J) }\end{array}$ & $\begin{array}{c}\text { Residual } \\
\text { Deformation } \\
(\mathbf{m m})\end{array}$ & $\begin{array}{c}\text { Time to } \\
\text { Peak Load } \\
(\mathrm{ms})\end{array}$ & $\begin{array}{c}\text { CAI } \\
\text { Strength } \\
\text { (MPa) }\end{array}$ \\
\hline $10 \mathrm{~J}$ & $\begin{array}{r}3611.19 \\
\pm(71.50)\end{array}$ & $\begin{array}{c}4.19 \\
\pm(0.16)\end{array}$ & $\begin{array}{c}3.09 \\
\pm(0.2)\end{array}$ & $\begin{array}{c}0.15 \\
\pm(0.09)\end{array}$ & $\begin{array}{c}2.16 \\
\pm(0.1)\end{array}$ & $\begin{array}{c}98.44 \\
\pm(1.72)\end{array}$ \\
\hline $15 \mathrm{~J}$ & $\begin{array}{r}4690.38 \\
\pm(67.92)\end{array}$ & $\begin{array}{c}5.11 \\
\pm(0.11)\end{array}$ & $\begin{array}{c}6.10 \\
\pm(0.29)\end{array}$ & $\begin{array}{c}0.45 \\
\pm(0.12)\end{array}$ & $\begin{array}{c}1.88 \\
\pm(0.2)\end{array}$ & $\begin{array}{c}89.33 \\
\pm(2.61)\end{array}$ \\
\hline $20 \mathrm{~J}$ & $\begin{array}{r}5329.81 \\
\pm(90.03)\end{array}$ & $\begin{array}{c}6.29 \\
\pm(0.10)\end{array}$ & $\begin{array}{c}9.43 \\
\pm(0.5)\end{array}$ & $\begin{array}{c}0.75 \\
\pm(0.10)\end{array}$ & $\begin{array}{c}2.16 \\
\pm(0.1)\end{array}$ & $\begin{array}{c}83.55 \\
\pm(1.27)\end{array}$ \\
\hline $25 \mathrm{~J}$ & $\begin{array}{r}5432.71 \\
\pm(51.50)\end{array}$ & $\begin{array}{c}7.36 \\
\pm(0.18)\end{array}$ & $\begin{array}{c}12.73 \\
\pm(0.46)\end{array}$ & $\begin{array}{c}1.64 \\
\pm(0.17)\end{array}$ & $\begin{array}{c}2.22 \\
\pm(0.1)\end{array}$ & $\begin{array}{c}79.11 \\
\pm(1.55)\end{array}$ \\
\hline $30 \mathrm{~J}$ & $\begin{array}{c}5618.91 \\
\pm(25.57)\end{array}$ & $\begin{array}{c}8.20 \\
\pm(0.1)\end{array}$ & $\begin{array}{c}17.51 \\
\pm(0.56)\end{array}$ & $\begin{array}{c}3.06 \\
\pm(0.25)\end{array}$ & $\begin{array}{c}1.96 \\
\pm(0.2)\end{array}$ & $\begin{array}{c}76.66 \\
\pm(1.33)\end{array}$ \\
\hline \multicolumn{7}{|c|}{ Filler Loaded Samples } \\
\hline $\begin{array}{c}\text { Impact } \\
\text { Energy } \\
(\mathrm{J})\end{array}$ & $\begin{array}{c}\text { Peak Load } \\
(\mathbf{N})\end{array}$ & $\begin{array}{c}\text { Max. } \\
\text { Deformation } \\
\quad(\mathbf{m m})\end{array}$ & $\begin{array}{c}\text { Absorbed } \\
\text { Energy } \\
\text { (J) }\end{array}$ & $\begin{array}{c}\text { Residual } \\
\text { Deformation } \\
\quad(\mathbf{m m})\end{array}$ & $\begin{array}{c}\text { Time to } \\
\text { Peak Load } \\
(\mathrm{ms})\end{array}$ & $\begin{array}{c}\text { CAI } \\
\text { Strength } \\
\text { (MPa) }\end{array}$ \\
\hline $10 \mathrm{~J}$ & $\begin{array}{r}3924.17 \\
\pm(91.57)\end{array}$ & $\begin{array}{c}4.08 \\
\pm(0.14)\end{array}$ & $\begin{array}{c}1.76 \\
\pm(0.2)\end{array}$ & $\begin{array}{c}0.1 \\
\pm(0.05)\end{array}$ & $\begin{array}{c}2.08 \\
\pm(0.2)\end{array}$ & $\begin{array}{r}117.55 \\
\pm(2.27)\end{array}$ \\
\hline $15 \mathrm{~J}$ & $\begin{array}{l}4801.85 \\
( \pm 36.13)\end{array}$ & $\begin{array}{c}4.96 \\
\pm(0.16)\end{array}$ & $\begin{array}{c}5.82 \\
\pm(0.34)\end{array}$ & $\begin{array}{c}0.32 \\
\pm(0.12)\end{array}$ & $\begin{array}{c}1.90 \\
\pm(0.1)\end{array}$ & $\begin{array}{r}111.77 \\
\pm(1.88)\end{array}$ \\
\hline $20 \mathrm{~J}$ & $\begin{array}{c}5797.07 \\
( \pm 90.31)\end{array}$ & $\begin{array}{c}6.01 \\
\pm(0.10)\end{array}$ & $\begin{array}{c}8.50 \\
\pm(0.5)\end{array}$ & $\begin{array}{c}0.68 \\
\pm(0.18)\end{array}$ & $\begin{array}{c}2.21 \\
\pm(0.1)\end{array}$ & $\begin{array}{r}108.22 \\
\pm(1.61)\end{array}$ \\
\hline $25 \mathrm{~J}$ & $\begin{array}{r}6161.56 \\
( \pm 75.33)\end{array}$ & $\begin{array}{c}6.88 \\
\pm(0.10)\end{array}$ & $\begin{array}{c}13.80 \pm \\
(0.54)\end{array}$ & $\begin{array}{c}1.52 \\
\pm(0.2)\end{array}$ & $\begin{array}{c}1.92 \\
\pm(0.2)\end{array}$ & $\begin{array}{r}101.55 \\
\pm(2.30)\end{array}$ \\
\hline $30 \mathrm{~J}$ & $\begin{array}{r}6137.06 \\
( \pm 57.57)\end{array}$ & $\begin{array}{c}7.98 \\
\pm(0.12)\end{array}$ & $\begin{array}{c}18.14 \\
\pm(0.62)\end{array}$ & $\begin{array}{c}2.4 \\
\pm(0.26)\end{array}$ & $\begin{array}{c}1.81 \\
\pm(0.1)\end{array}$ & $\begin{array}{c}97.11 \\
\pm(2.55)\end{array}$ \\
\hline
\end{tabular}


